\title{
Redução de Riscos e Danos: Ações em Saúde com Pessoas em Situação de Rua no Interior Nordestino
}

\author{
Leonardo Magela Lopes Matoso, ${ }^{1}$ Joatan Jonas dos Santos Silva, ${ }^{2}$ \\ Barbara Medeiros do Nascimento, ${ }^{3}$ Mônica Betania Lopes Matoso ${ }^{4}$
}

\begin{abstract}
RESUMO
Objetivo: descrever a experiência de ações em saúde desenvolvidas com pessoas em situação de rua visando à redução de riscos e danos. Método: foram realizadas ações com 22 pessoas ao longo de três meses, cujo objetivo foi promover medidas de diminuição de riscos e danos. Realizou-se estudo de caráter descritivo e natureza exploratória, do tipo relato de experiência. Resultados e Discussão: os resultados apontaram que das 22 pessoas em situação de rua, $82 \%$ eram do gênero masculino, 64\% pardos, 68\% com idade entre 30 e 59 anos, 54\% possuíam Ensino Fundamental incompleto e $50 \%$ relacionavam-se com familiares, no entanto saíram de casa devido a conflitos desestruturantes. A droga de maior consumo foi o crack (23\%) e álcool (23\%) e suas associações, como crack e maconha (18\%). Conclusão: as ações de redução de riscos e danos em saúde (imunização, orientação, aferição de sinais vitais e alimentação) contribuíram para uma assistência mais acolhedora, equânime e pautada na subjetividade, dignidade, saúde e bem-estar de cada indivíduo. Além disso, fomentou-se momentos de autonomia no processo de autocuidado das pessoas em situação de rua, suscitando reflexões acerca do uso de álcool e outras drogas.
\end{abstract}

Palavras-chave: Pessoas em situação de rua. Usuários de drogas. Vulnerabilidade social.

\section{REDUCTION OF RISKS AND DAMAGES: HEALTH ACTIONS WITH PEOPLE IN STREET SITUATION IN THE NORTH-EAST}

\section{ABSTRACT}

Objective: describe the experience of health actions developed with people in a street situation aimed at reducing risks and damages. Method: actions were carried out with 22 people during three months, whose objective was to promote measures of risk reduction and damages. A descriptive and exploratory nature of the type of experience was carried out. Results and Discussion: the results showed that of the 22 people in the street, $82 \%$ were male, $64 \%$ were brown, $68 \%$ were aged between 30 and 59 years. Where $54 \%$ had incomplete elementary education and $50 \%$ related to relatives, nevertheless they left home due to destructive conflicts. The drug with the highest consumption was crack $(23 \%)$ and alcohol $(23 \%)$ and its associations, such as crack and marijuana (18\%). Conclusion: actions to reduce health risks and damages (immunization, orientation, vital signs and food) contributed to a more welcoming, equitable and guided assistance in the subjectivity, dignity, health and well-being of everyone. In addition, moments of autonomy were fostered in the homeless persons self-care process, provoking reflections on the use of alcohol and other drugs.

Keywords: Homeless persons. Drug users. Social vulnerability.

\footnotetext{
Mestre Interdisciplinar em Cognição, Tecnologias e Instituiç̧̃es da Universidade Federal Rural do Semiárido (Ufersa). Especialista em Acupuntura pela Associação Brasileira de Acupuntura (ABA). Especialista em Saúde e Segurança no Trabalho pela Faculdade de Enfermagem Nova Esperança (Facene). Enfermeiro graduado pela Universidade Potiguar (UNP). Discente de Jornalismo da Universidade do Estado do Rio Grande do Norte (Uern). leonardo.I.matoso@gmail.com

${ }^{2}$ Mestrando em Arquitetura e Urbanismo pela Universidade Federal do Rio Grande do Norte (UFRN). Pós-graduando em Master BIM: Ferramentas de Gestão e Projeto pelo Instituto de Pós-Graduação e Graduação (Ipog). Engenheiro Civil pela Universidade Potiguar (UnP) e Técnico em Edificações pelo Instituto Federal do Rio Grande do Norte (IFRN). Mossoró/RN. joatan.j.santos@gmail.com

${ }^{3}$ Especialista em Saúde e Segurança no Trabalho pela Faculdade de Enfermagem Nova Esperança (Facene). Enfermeira graduada pela Universidade Potiguar (UNP), Campus Mossoró/RN. barbaramedeiiros@hotmail.com

${ }^{4}$ Especialista em Pluralidade Cultural e Orientação Sexual pela Universidade do Estado do Rio Grande do Norte (Uern). Especialista em Regulação em Saúde no SUS, pelo Instituto Sírio-Libanês de Ensino e Pesquisa (IEP/HSL). Graduada em Serviço Social pela Universidade do Estado do Rio Grande do Norte (Uern). monicabetania@yahoo.com.br
} 


\section{INTRODUÇÃO}

Atuar com Pessoas em Situação de Rua (PSRs) é tentar trabalhar com fragmentos de um grupo estigmatizado, excluído e marcado por intenso preconceito e sofrimento social. É buscar incessantemente que estas pessoas, tidas como "descartáveis urbanas", sejam visibilizadas e incluídas a partir do reconhecimento de suas vulnerabilidades e potencialidades na sociedade por meio das políticas públicas. Para Alcântara, Abreu e Farias (2015), PSRs são aquelas que vivem na e da rua em caráter de transitoriedade, de absoluta exclusão social e que adotam como moradia logradouros da cidade, casas abandonadas, praças, cemitérios, carcaças de veículos, terrenos baldios ou depósitos de papelão e sucata. Estas pessoas são marcadas pela pobreza extrema, com vínculos familiares interrompidos, fragilizados e sem moradia convencional regular.

Adorno (2013) defende que PSRs, quando não ignoradas, são tratadas como objetos da tutela do Estado, da filantropia privada ou da caridade das pessoas e das igrejas. As condições precárias acompanhadas de perdas individuais podem refletir na saúde física e mental das pessoas que têm a rua como local para viver. Além disso, o consumo de drogas ilícitas e lícitas mostra-se preponderante nas causas que levam estes indivíduos às ruas ou que ao viverem a situação de rua passam a utilizá-las, como forma de suportar a situação.

Os agravos oriundos da dependência comprometem a saúde, a dinâmica familiar e social do usuário. Assim, neste cenário de alta vulnerabilidade, as PSRs podem ser expostas, cotidianamente, a diversos fatores de risco pessoal e social, tornando-se mais vulneráveis à violência e ao consumo de álcool e outras drogas (BISCOTTO et al., 2016).

Segundo alguns autores (FERREIRA; ROZENDO; MELO, 2016.; BISCOTTO et al., 2016), droga é qualquer Substância Psicoativa (SPA) não produzida pelo organismo que tem a propriedade de atuar sobre um ou mais sistemas orgânicos, produzindo reações em seu funcionamento capaz de alterar o desempenho do Sistema Nervoso Central (SNC).

Pelo exposto, pontifica-se que a expansão do consumo de SPAs - especialmente álcool, cocaína, crack e inalantes - tem interferido na saúde e na qualidade de vida das PSRs, além de atingir toda a sociedade. Estudo realizado pelo Instituto de Pesquisa Econômica Aplicada (Ipea) em 2015 apontou que no Brasil existem cerca de 101.854 PSRs, das quais 6,63\% encontram-se em cidades com até 10 mil habitantes e $40,1 \%$ vivem em municípios maiores, com mais de
100 mil pessoas (NATALINO, 2016). Dos indivíduos que residem na rua, alguns autores (FERREIRA; ROZENDO; MELO, 2016.; ALCÂNTARA, ABREU, FARIAS, 2015.; BISCOTTO et al., 2016) observam que boa parte faz uso de SPAs. O uso do álcool e outras drogas é relatada como única alternativa possível de suportar a total vulnerabilidade inerente à vida nas ruas e opera como mediadora de relações sociais e de sobrevivência. Salienta-se que em termos estatísticos não se pode inferir ao certo o percentual de álcool e outras drogas consumido pelas PSRs, pois no Brasil estudos que abordem estas inferências são escassos, contudo discussões nacionais trazem à tona questões relativas a essas pessoas, como a necessidade de ações que reforcem os cuidados sem estigmatizar a condição do usuário. Nesta perspectiva, tem-se a Redução de Riscos e Danos (RRD).

Segundo Silva, Frazão e Linhares (2014), a RRD caracteriza-se como uma abordagem ao fenômeno das drogas que visa a minimizar danos sociais à saúde associados ao uso de SPAs, sem necessariamente reduzir a quantidade e a frequência do uso. A redução de danos não objetiva agir diretamente sobre a demanda ou diminuição da oferta, propondo-se à desestigmatização e descriminalização dos usuários e, para isso, executa ações voltadas à prevenção e cuidado do que pode se constituir como danoso no uso das drogas.

A adoção da RRD como estratégia ao atendimento das PSRs pode contribuir para a criação de práticas de promoção em saúde e minimização de doenças e outros agravos. Além disso, as ações de RRD propiciam um olhar diferenciado da assistência praticada atualmente pelos profissionais da saúde, que muitas vezes restringem os cuidados com base em princípios pessoais e diretivos. Essa restrição leva às imposições institucionais e sociais que não têm a menor condição de serem cumpridas, como a exigência de abstinência como condição para o tratamento. Tais imposições têm feito com que usuários que necessitam de atenção em saúde fiquem sem assistência: os serviços de saúde não consideram aceitáveis alternativas à abstinência, como diminuir o consumo de algumas drogas ou eventualmente trocar por outras consideradas menos problemáticas.

Nesse sentido, compreender a vida na rua e o uso do álcool e outras drogas é algo desafiador e complexo, sobretudo no atual cenário epidemiológico nacional e local, no entanto é de extrema necessidade para a realização de ações e debates em prol das PSRs, na perspectiva de reinseri-las socialmente, com base no que advogam as políticas públicas vigentes. 
Diante deste contexto, a responsabilidade de profissionais e pesquisadores é pensar nos caminhos de mudança numa perspectiva ampliada de valorização da vida e de exercício da cidadania. Neste processo de mudança o saber e o fazer devem estar intimamente entrelaçados, a fim de possibilitar novos olhares e novos dispositivos de cuidado articulados para uma atenção integral às pessoas que vivenciam o uso de álcool e outras drogas em situação de rua. Assim, o objetivo deste estudo foi descrever a experiência de ações em saúde desenvolvidas com pessoas em situação de rua visando à redução de riscos e danos.

\section{MÉTODO}

Trata-se de um estudo de abordagem qualitativa, de caráter descritivo e natureza exploratória, do tipo relato de experiência a respeito de ações em saúde desenvolvidas com PSR visando a RRD (VERGARA, 2016). Esta experiência aconteceu no município de Mossoró, no RN, adotando como cenário os espaços da rua, mais especificamente uma praça no centro da cidade. Destaca-se que esta praça abriga diversas PSRs, por ser central e por possibilitar uma sensação de segurança. Além desses fatores, tem sua infraestrutura composta por diversos bancos compridos e uma fonte de água central, a qual as PSRs utilizam para fazer sua higiene e sanar a sede. Estima-se que a cidade de Mossoró possui aproximadamente 146 PSRs. Diante do exposto, o público-alvo desta intervenção foram estas pessoas que frequentavam ou viviam na praça.

Frisa-se que devido à característica das PSRs, entre as quais boa parte são dependentes de SPAs e encontram-se sob efeito destas substâncias, realizar medidas de RRD de forma coletiva, com rodas de conversas, atividades lúdicas ou dinâmicas, por exemplo, é uma tarefa complexa e dificultosa. Além disso, a rotatividade destas pessoas é um elemento que dificulta o encontro dessas pessoas e sua permanência no local de intervenção.

Tomando, no entanto, como pressuposto lógico, que PSRs, entre suas vulnerabilidades e situações fragilizadoras, são pessoas que não têm suas Necessidades Humanas Básicas (NHBs) satisfeitas, adotou-se, durante todos os encontros com as PSRs, um momento de "Refeição Solidária". Esse momento objetivou, além de alimentá-los, construir um vínculo humanista, profissional e de confiança. Essa estratégia da refeição parte da concepção de que é preciso ter ao menos uma das NHBs satisfeitas, como explicita a hierarquia de necessidades de Abraham Maslow, adotada e reformulada por Wanda Horta (2011). Quando uma das NHBs não está satisfeita o indivíduo tem sua homeostasia quebrada, ou seja, ele não consegue se autorrealizar, ter qualidade de vida e tampouco saúde. E no prisma dessa base teórica a necessidade de alimentação é basilar, sem ela o indivíduo não existe. Sendo assim, foi preciso primeiro alimentar as PSRs para depois realizar as medidas de RRD, pois uma vez alimentados eles, por conta própria, direcionaram sua atenção e suas necessidades para outros elementos.

Desse modo, as ações que foram realizadas na intervenção foram:

1. Exame clínico (anamnese e exame físico): Nesta ação foi possível coletar, mesmo que de forma sucinta, o histórico clínico das PSRs bem como alguns sinais e sintomas sugestivos de úlceras, problemas hepáticos, câncer e hipertensão arterial. Foi utilizada técnica de escuta qualificada, em que o diálogo foi direcionado às necessidades socioassistenciais das PSRs. Além disso, utilizou-se, luvas de procedimento, estetoscópio, esfigmomanômetro, termômetro, glicosímetro, álcool a $90 \%$, algodão, biombos, macas, fitas para o glicosímetro e oxímetro de pulso no exame físico.

2. Imunização: Por meio de vacinas disponibilizadas pela Secretaria Municipal de Saúde (SMS), as PSRs foram imunizadas com Dupla Adulto, Tríplice Viral e Influenza.

3. Orientações em saúde: As orientações em saúde ocorreram com base na clínica de abordagem sindrômica das Infecções Sexualmente Transmissíveis (ISTs), orientação e aconselhamento em relação à prevenção e ao tratamento de doenças e RRD ao consumo de substâncias psicoativas. As orientações foram realizadas durante todos os encontros, pois o intuito era construir vínculos de confiança a ponto de empoderar as PSRs e torná-las autônomas no processo de autocuidado, para que pudessem ir por conta própria à Unidade Básica de Saúde (UBS) da região.

Frisa-se que as ações ocorreram, quinzenalmente, nos meses de setembro, outubro e novembro de 2017, predominantemente no período noturno, com vistas a uma melhor visualização da população-alvo. Destaca-se que em todas as ações de RRD foram oferecidas refeições e doação de roupas, calçados e lençóis às PSRs.

\section{RESULTADOS E DISCUSSÃO}

As ações em saúde realizadas neste relato de experiência aconteceram em cinco momentos. No início das ações interventivas remeteu-se ao cenário de 
pesquisa com objetivo de construir vínculos, conhecer as PSRs e o ambiente no qual as ações iriam ocorrer. Em média, participaram deste primeiro momento, 47 PSRs, quando foram realizadas rodas de conversas e entrega de roupas e de refeições. No segundo momento foram realizados exames clínicos e anamneses com 38 PSRs. Frisa-se que neste momento as PSRs mostraram-se resistentes, apreensivas e temerosas. Boa parte em virtude do uso de SPA, em outros, por desacreditarem neste tipo de serviço, ao alegarem já terem sido alvo de ações descontinuadas e sem impacto significativo em suas necessidades.

Para Alcântara, Abreu e Farias (2015), estas ações descontinuadas revelam um problema de fragilização do Sistema Único de Saúde (SUS) no que concerne à realização de ações com PSRs. A saúde destas pessoas é intensamente comprometida devido às dificuldades de acesso aos serviços públicos de saúde do país. Um dos princípios do SUS é garantir acesso universal, integral e com equidade aos serviços de saúde, mas, na prática, essas ações não funcionam. Esse é um dos principais fatores que dificultam a assistência às PSRs, mostrando a escassez de modelos voltados à atenção a esse segmento da população.

Com relação ao terceiro momento, que a priori idealizava-se aplicação de vacinas, o mesmo não aconteceu em sua completude. A vacinação foi comprometida neste momento em razão do surgimento da Polícia Civil que acompanhava os profissionais técnicos do Centro de Referência Especializado de Assistência Social (Creas). Em virtude do surgimento da Polícia, muitas PSRs foram embora e não foram concluídas as vacinações. Assim, devido essa evasão e receio do público com a polícia local, foi realizada apenas a refeição solidária.

A abordagem social feita pela equipe do Creas, ao ser escoltada pela Polícia Civil, tende a repelir as PSRs, uma vez que muitos destes já foram vítimas da própria Polícia ou temem essa categoria de profissionais (RESENDE, 2015). Desta forma a PSR não aceita e não participa dos serviços ofertados pela equipe do Creas. Sabe-se que a aceitação, adesão e permanência dos usuários ao serviço é voluntária, não sendo permitido à equipe obrigá-los a qualquer tipo de participação. Sendo assim, é necessário rever a forma de abordagem feita pela equipe do Creas.

Na ótica de Ferreira, Rozendo e Melo (2016), a presença da Polícia Civil em ações de saúde é desnecessária principalmente com grupos vulnerabilizados e marginalizados socioculturalmente. É papel dos serviços de saúde construir vínculos de segurança, afetividade, humanização e respeito quando lidam com PSRs. A presença da Polícia Civil durante a condução de ações profiláticas dificulta a criação destes vínculos e desestimula o indivíduo a retomar a assistência.

Por sua vez, no quarto e quinto momentos deu-se sequência às ações que haviam sido planejadas. Salienta-se, no entanto, que houveram algumas dificuldades, pois neste período aconteceram dois homicídios de PSR e a Polícia Civil estava fazendo rondas no local. Participaram destes momentos 22 PSRs, quando foram realizadas aferições dos sinais vitais, orientações em saúde, imunização e uma pequena entrevista. Salienta-se que essas 22 PSRs foram assistidas desde do primeiro momento, tendo um acompanhamento continuado em todos os encontros. Sendo assim, essas 22 PSRs constituíram o corpus deste estudo.

Diante do exposto, foi possível verificar por meio das ações realizadas a inexistência de políticas públicas que contemplassem as necessidades das PSRs. Pontifica-se ainda que as mesmas dificuldades relatadas neste relato de experiência foram vivenciadas nos estudos de Ferreira, Rozendo e Melo (2016), assim como nos trabalhos de Alcântara, Abreu e Farias (2015).

O perfil sociocultural das PSRs atendidas durante os cinco momentos foi predominantemente masculino, representando um total de $82 \%$ dos usuários que se encontravam em situação de rua. Com relação à idade, observou-se uma predominância de $68 \%$ entre 30 e 59 anos. É importante salientar ainda, que entre o público, $64 \%$ se identificavam como pardos. No tocante à escolaridade, foi possível constatar que 54\% possuíam Ensino Fundamental incompleto.

Estudos apontam (SILVA; FRAZÃO; LINHARES, 2014.; RESENDE, 2015.; CARNEIRO; PROCÓPIO, 2018) que PSRs são geralmente do sexo masculino, com idade entre 25 e 44 anos e que nunca estudaram ou não concluíram o Ensino Fundamental. A baixa escolaridade é apontada nestes estudos como um dos fatores que levam estes indivíduos a vivenciarem as ruas e envolverem-se com álcool e outras drogas.

A fim de compreender os fenômenos que contribuíram significativamente para a atual situação de rua, os PSRs foram questionados se tinham familiares, e a partir desta indagação foram investigados quais motivos os levaram a sair de casa. Diante desse questionamento foi identificado que $50 \%$ possuíam familiares, porém estes não aceitavam as drogas. Esse processo de não aceitação corroborou para a moradia nas ruas. A Tabela 1 aponta os achados desta intervenção. 
Tabela 1 - Identificação sociocultural das PSRs, em novembro de 2017

\begin{tabular}{ccc}
\hline Gênero & $\mathbf{n .}$ & $\%$ \\
Masculino & 18 & $82 \%$ \\
Feminino & 4 & $18 \%$ \\
Faixas de Idade & $\mathbf{n .}$ & $\%$ \\
\hline Entre18 e 29 anos & 3 & $14 \%$ \\
Entre 30 e 59 anos & 15 & $68 \%$ \\
Acima de 60 & 4 & $18 \%$ \\
Raça & $\mathbf{n .}$ & $\%$ \\
Branco & 2 & $9 \%$ \\
Pardo & 14 & $64 \%$ \\
Negro & 6 & $27 \%$ \\
Escolaridade & $\mathbf{n .}$ & $\%$ \\
\hline Ensino Fundamental Incompleto & 12 & $54 \%$ \\
Ensino Fundamental Completo & 4 & $18 \%$ \\
Ensino Médio Completo & 6 & $28 \%$ \\
\hline Tem Família & $\mathbf{n .}$ & $\%$ \\
\hline Sim, mas não aceitam que usem drogas & 11 & $50 \%$ \\
Sim, mas decidi sair devido abuso sexual & 7 & $32 \%$ \\
Sim, mas são violentos & 2 & $9 \%$ \\
Não, morreram & 2 & $9 \%$ \\
\hline Fo
\end{tabular}

Fonte: Acervo dos autores, 2017.

Após a identificação inicial das pessoas que viviam em situação de rua, buscou-se compreender como estavam as questões clínica e assistencial. Para tanto, foram questionadas quanto a apresentar alguma queixa (sinais e sintomas), a droga de uso, se já haviam buscado tratamento ou não, e tiveram seus sinais vitais verificados.

Durante a condução das ações alguns casos em particular chamaram atenção. O primeiro foi uma senhora, que afirmava não lembrar a idade e apresentava uma higiene precária por todo o corpo. Segundo pessoas que estavam no local durante as ações de RRD, esta senhora havia sido violentada sexualmente várias vezes quando estava bêbada e dormindo na praça. Este fato, segundo relatos, já foi informado à Polícia, mas nada aconteceu. Com base no exame físico realizado, foi identificado um caroço (nódulo) no ânus e vagina, sugestivo de Condiloma Acuminado ou Papiloma Vírus Humano (HPV).

Outro caso, que suscitou uma gama de reflexões refere-se a dois rapazes que buscaram tratamento, no entanto acabaram fugindo. Um deles alegou ter passado 12 dias em uma clínica e não aguentou a abstinência, pois para permanecer no local era preciso não ingerir nenhuma substância. $\mathrm{O}$ outro, além dos problemas com álcool e drogas, adquiriu tuberculose na rua. Foi internado em um hospital especializado para doenças infectocontagiosas na cidade e devido a questões de abstinência também fugiu, abandonando o tratamento.
Esses casos relatados trazem à tona uma gama de discussões, principalmente no que respeita ao modelo assistencial burocratizado de tratamento e reabilitação imposta pela rede de saúde às pessoas com dependência (CARNEIRO; PROCÓPIO, 2018). A necessidade de ações mais intensas e a modificação do modelo assistencial direcionado para esse público corrobora um questionamento: Até onde, na condição de rede de saúde, o nosso papel é realizado de modo eficaz e desburocratizado? É notório que ainda hoje os centros de reabilitação a pessoas dependentes de álcool e outras drogas reforçam a ideia de que para buscar tratamento é importante a abstinência, como se esta fosse a única alternativa de reabilitação e tratamento para esse público.

Indagados sobre possuírem alguma queixa, 50\% relataram sentir fortes dores musculares nos membros inferiores, superiores e no pescoço. Sobre a droga de uso, 22\% alegaram utilizar apenas álcool. Quanto a buscar tratamento, $77 \%$ explicitaram que nunca foram atrás de tratamento, pois não acreditam nas ações em saúde de forma continuada. Ademais, destaca-se, quanto aos sinais vitais, que $54 \%$ estavam com pressão arterial alterada, maior que $140 \times 90 \mathrm{mmHg}, 64 \%$ possuíam a respiração nos parâmetros de normalidade, entre 12 e 20 irpm. Quanto ao pulso, 50\% estavam alterados, entre 82 e 95 bpm e $86 \%$ estavam afebris. A Tabela 2 revela esses dados de forma categórica.

Tabela 2 - Variáveis clínicas das PSRs identificadas no município de Mossoró/RN, em novembro de 2017

\begin{tabular}{|c|c|c|}
\hline Queixas & n. & $\%$ \\
\hline Dores musculares (pernas, braços e pescoço) & 11 & $50 \%$ \\
\hline Angina & 4 & $18 \%$ \\
\hline Angústia & 3 & $14 \%$ \\
\hline Pensamentos Suicida & 2 & $9 \%$ \\
\hline Taquicardia & 2 & $9 \%$ \\
\hline Drogas de Uso & n. & $\%$ \\
\hline Álcool & 5 & $22 \%$ \\
\hline Maconha & 5 & $22 \%$ \\
\hline Crack & 4 & $19 \%$ \\
\hline Álcool e Maconha & 4 & $19 \%$ \\
\hline Álcool e Crack & 3 & $14 \%$ \\
\hline Álcool, Maconha e Crack & 1 & $4 \%$ \\
\hline Já Buscou Tratamento & n. & $\%$ \\
\hline Não & 17 & $77 \%$ \\
\hline Sim & 5 & $23 \%$ \\
\hline Sinais Vitais & n. & $\%$ \\
\hline Pressão Arterial Normal & 10 & $45 \%$ \\
\hline Pressão Arterial Alterada & 12 & $54 \%$ \\
\hline Respiração Normal & 14 & $64 \%$ \\
\hline Respiração Alterada & 8 & $36 \%$ \\
\hline Pulso Normal & 11 & $50 \%$ \\
\hline Pulso Alterado & 11 & $50 \%$ \\
\hline Temperatura Normal & 19 & $86 \%$ \\
\hline Temperatura Alterada & 3 & $14 \%$ \\
\hline
\end{tabular}

Fonte: Acervo dos autores, 2017. 
Além das inferências tecidas até aqui, as PSRs foram indagadas sobre o que era saúde, segundo suas concepções. Com base neste questionamento e na análise realizada apreendeu-se que para elas, "saúde era não usar drogas, era não ficar doente por causa das drogas". Melhor que isso, saúde era "acordar todos os dias tendo o que comer, é ter para onde retornar no começo da noite, é sentir o cheiro de estar em família".

As concepções de saúde para estas pessoas estão associadas à capacidade de não usar drogas, de estar vivo e de resistir ao cotidiano das dificuldades nas ruas (CUNHA et al., 2017). Atrelado a isso, é notório que as dificuldades familiares e os conflitos são os fatores, em sua grande maioria, que os impulsionaram a estar na rua, como também é o fator de maior lembrança e de "ser saudável", uma vez que ficar em casa seria sinônimo de adoecimento tanto físico como mental. Com isso, foi preferível ir para as ruas vivencias situações sem conflitos familiares do que ficar em casa (CARNEIRO; PROCÓPIO, 2018), o que aponta para a importância da família diante dessa problemática e a necessidade de reajustar os laços familiares ou de não os comprometer.

Com base neste cenário é fácil observar que o trabalho desenvolvido inicialmente com PSRs no município de Mossoró possibilitou vislumbrar um leque de ações necessárias para o atendimento deste públi$\mathrm{co}$, no entanto cabe aqui ressaltar que algumas questões merecem destaque para análise e construção de alternativas de resolução diante da problemática discutida. É premente a necessidade de planejamento estratégico tanto no âmbito dos serviços ofertados pelo Creas de Mossoró, assim como uma articulação sistemática deste equipamento social com as instituições representativas de outras políticas públicas que possibilitem um atendimento às PSRs de modo sistemático, humanista, resoluto e equânime.

\section{CONCLUSÃO}

Após análise dos dados foi possível descrever o perfil sociocultural das PSRs, suas concepções e necessidades. As ações em saúde (imunização, orientação, aferição de sinais vitais e alimentação) contribuíram para uma assistência mais acolhedora, equânime e pautada na subjetividade, dignidade, saúde e bem-estar de cada indivíduo. Sucintamente, os resultados apontaram uma predominância de homens em situação de rua, na faixa-etária entre 30 e 59 anos, com Ensino Fundamental incompleto e com conflitos familiares desestruturantes. As drogas de maior consumo foram o crack e álcool, bem como crack e maconha. Diante disso, e das ações em saúde com ênfase na RRD, conclui-se que este estudo conseguiu alcançar o objetivo proposto, ao descrever a experiência de ações em saúde desenvolvidas com PSRs. Além disso, fomentou momentos de autonomia no processo de autocuidado das PSRs, para que pudessem ir por conta própria à UBS da região.

Dessa forma, os resultados fornecem um indicador sobre as PSRs no município, bem como sua problemática em âmbito nacional. Além disso, o estudo pretende contribuir com subsídios para a elaboração de políticas e programas de saúde que visem, de forma efetiva, à construção/reestruturação de vínculos das PSRs, bem como cuidados em saúde na perspectiva da RRD que contribuam para uma melhor qualidade de vida.

\section{REFERÊNCIAS}

ADORNO, R. de C. F. Atenção à saúde, direitos e o diagnóstico como ameaça: políticas públicas e as populações em situação de rua. Etnográfica, v. 15, n. 3, p. 543-567, 2013.

ALCANTARA, S. C.; ABREU, D. P.; FARIAS, A. A. Pessoas em situação de rua: das trajetórias de exclusão social aos processos emancipatórios de formação de consciência, identidade e sentimento de pertença. Revista Colombiana de Psicología, v. 24, n .1, p. 129-143, 2015.

BISCOTTO, P. R.; JESUS, M. C. P.; SILVA, M. H.; et al. Understanding of the life experience of homeless women. Revista de Enfermagem da USP, v. 50, n. 5, p. 749-755, 2016.

CARNEIRO, A. C.; PROCÓPIO, M. R. Os imaginários sciodiscursivos das pessoas em situação de rua através dos relatos do projeto sp invisível. Revista Anagrama: Revista Científica Interdisciplinas da Graduação, v. 12, n. 1, p. 1-15, 2018.

CUNHA, J. G. et al. Novos arranjos: lançando um olhar sobre os relacionamentos interpessoais de pessoas em situação de rua. Gerais: Revista Interinstitucional de Psicologia, v. 10, n. 1, p. 95-108, 2017.

FERREIRA, C. P. S.; ROZENDO, C. A.; MELO, G. B. Consultório na rua em uma capital do nordeste brasileiro: o olhar de pessoas em situação de vulnerabilidade social. Caderno de Saúde Pública, v. 32, n. 8, p. 1-10, 2016.

HORTA, W. Processo de enfermagem. 10. ed. São Paulo: Guanabara Koogan, 2011.

NATALINO, M. A. C. Estimativa da população em situação de rua no Brasil. 1. ed. São Paulo: Instituto de Pesquisa Econômica Aplicada, 2016.

RESENDE, V. M. A violação de direitos da população em situação de rua e a violência simbólica: representação discursiva no jornalismo on-line. Revista Latinoamericana de Estudios del Discurso, v. 15, n. 1, p. 71-91, 2015.

SILVA, F. P.; FRAZÃO, I. S.; LINHARES, F. M. P. Práticas de saúde das equipes dos Consultórios de Rua. Caderno de Saúde Pública, v. 30, n. 6, p. 805-814, 2014.

VERGARA, S. C. Projetos e relatórios de pesquisa em administração. 16. ed. São Paulo: Editora Atlas, 2016. 